\title{
Effect of Tungsten Carbide Particles on the Characteristics of PEO Coatings Formed on AZ31B Magnesium Alloy in Alkaline Electrolyte
}

\author{
Yang Zhang, Yaling Xu, Chengping Miao, Xiaohua Tu*, Jianxing Yu, Jiayou Li
}

College of Biological and Chemical Engineering, Jiaxing University, Zhejiang, Jiaxing 314001, China;

Key Laboratory of Clean Chemical Process of Jiaxing, Zhejiang, Jiaxing 314001, China

E-mail: tuxiaohua@mail.zjxu.edu.cn

doi: $10.20964 / 2018.08 .42$

Received: 16 March 2018 / Accepted: 9 May 2018 / Published: 5 July 2018

The oxide coatings were prepared on AZ31B magnesium alloy in the alkaline electrolyte with and without tungsten carbide (WC) particles by plasma electrolytic oxidation. The phase composition and surface morphology of the coatings were studied using X-ray diffraction (XRD) and scanning electron microscopy (SEM), respectively. The anticorrosion performance of coatings was investigated by potentiodynamic polarization tests in $3.5 \mathrm{wt} \% \mathrm{NaCl}$ solution. It was found that a more uniform and compact oxide coating with less micropores and cracks was formed in the alkaline electrolyte with WC particles. The XRD results showed that the coating formed in the electrolyte with WC particles mainly contains $\mathrm{MgO}, \mathrm{MgSiO}_{3}, \mathrm{Mg}_{2} \mathrm{SiO}_{4}$, and $\mathrm{WC}$. The anticorrosion performance of the magnesium alloy was significantly improved by plasma electrolytic oxidation in the alkaline electrolyte with WC particles, as indicated in the results of potentiodynamic polarization tests.

Keywords: AZ31B magnesium alloy; plasma electrolytic oxidation; tungsten carbide; corrosion resistance

\section{$\underline{\text { FULL TEXT }}$}

(C) 2018 The Authors. Published by ESG (www.electrochemsci.org). This article is an open access article distributed under the terms and conditions of the Creative Commons Attribution license (http://creativecommons.org/licenses/by/4.0/). 